\title{
Gallium Ga 68-P16-093
}

National Cancer Institute

\section{Source}

National Cancer Institute. Gallium Ga 68-P16-093. NCI Thesaurus. Code C148484.

A radioconjug ate composed of a human prostate specific membrane antigen (PSMA)targeting ligand (P16-093) conjug ated to the radioisotope gallium Ga 68, via the acyclic radiometal chelator N,N'-bis [2-hydroxy-5-(carboxyethyl)benzyl] ethylenediamine-N,N'diacetic acid (HBED-CC), with potential use as a tracer for PSMA-expressing tumors during positron emission tomography (PET). Upon intravenous administration of the gallium Ga 68 P16-093, the P16-093 moiety targets and binds to PSMA-expressing tumor cells. During PET imaging, PSMA-expressing tumor cells can be detected. PSMA, a tumor-associated antigen (TAA) and type II transmembrane protein, is expressed on the membrane of prostatic epithelial cells and overexpressed on prostate tumor cells. 